\title{
Konya Şartlarında Seleksiyon ile Geliştirilen Aspir Hatlarının Verim ve Verim Unsurları Bakımından Değerlendirilmesi
}

\author{
Hasan $\mathrm{KOÇ}^{1}$ \\ Ahmet GÜNEŞ ${ }^{1}$ \\ Seydi AYDOĞAN ${ }^{1}$ \\ ${ }^{1}$ Bahri Dağdaş Uluslararası Tarımsal Araştırma Enstitüsü Müdürlüğü, KONYA \\ $\triangle$ : koc175@hotmail.com
}

Geliş (Received): 03.11.2017

Kabul (Accepted): 15.12.2017

\begin{abstract}
ÖZET: Bu çalışma 2015 ve 2016 yıllarında Orta Anadolu Bölgesi aspir ıslah çalışmaları kapsamında elde edilen ileri kademedeki beş adet aspir hatları (106-2, 11-1, 77-1-d, 89-1-c, BDYAS-9) ile standart çeşitlerin (Göktürk, Balcı, Linas, Olas, Dinçer) verim ve verim unsurları yönünden karşılaştırılması amacıyla yapılmıştır. Bu amaçla çeşit ve hatların tohum verimi, yağ oranı ve yağ verimleri tespit edilmiştir. Aspir hat geliştirme çalışmalarımız ABD Gen bankasından temin edilen 245 adet aspir popülasyonları ile 2008 yılında başlamıştır. 2008 yılından 2015 yılına kadar hatlar, çeşitli özellikler yönünden seleksiyona tabi tutulmuştur.2015 ve 2016 yıllarında 5 adet standart çeşit ve 5 adet hatla, tesadüf blokları deneme desenine göre dört tekerrürlü olarak Konya Bahri Dağdaş Uluslararası Tarımsal Araştırma Enstitüsü deneme tarlalarında verim denemesi kurulmuştur. Aspir hatları arasında tohum verimi bakımından her iki yılda da önemli farklılıklar bulunmuştur. Aynı şekilde yılların birleştirilmesi ile yapılan analiz de farklılığı ortaya koymuştur. İki yıl ortalamasına göre BDYAS-9 nolu hattımız $302 \mathrm{~kg} / \mathrm{da}$ tohum verimi ile ilk sırada yer alırken, bunu sırasıyla $289 \mathrm{~kg} / \mathrm{da}$ ve $285 \mathrm{~kg} / \mathrm{da}$ ile Dinçer ve Göktürk çeşitleri takip etmiştir. Yağ oranı bakımından ise BDYAS-9 nolu hattımız \%37.7 lik yă̆ oranı ile birinci sırada yer almış, bunu \%37 ile Olas ve \% 35.1 ile Linas çeşitleri takip etmiştir. İki yıl ortalamasına göre BDYAS-9 nolu hattımızdan 113,5 kg/da yağ verimi elde edilirken, Olas çeşidinden 100,Linas çeşidinden 95, Balcı çeşidinden $90 \mathrm{~kg} / \mathrm{da}$ yağ verimi elde edilmiştir. Tohum verimi, yă̆ oranı ve yağ verimi açısından mevcut çeşitlerden daha üstün özellikleri olan çeşitlerin geliştirilmesi, aspir tarımında ekonomik olarak ürün elde edilmesi, hem çiftçinin hem de sanayicinin tercih etmesi açısından önem arz etmektedir.
\end{abstract}

Anahtar Kelimeler: Aspir, seleksiyon, çeşit, sslah

\section{Evaluation of Yield and Yield Components of Safflower Lines Developed by Selection in Konya Conditions}

ABSTRACT: This study was carried out in order to compare the five types of safflower lines(106-2, 11-1, 77-1-d, 89-1-c, BDYAS-9 advanced stage obtained in the Central Anatolian Region safflower improvement studies with the standard varieties(Göktürk, Balc1, Linas, Olas, Dinçer) in terms of yield and yield components in 2015 and 2016. For this purpose, seed yield, oil content and oil yield of the varieties and lines were determined.

Safflower line development studies began with 245 safflower populations obtained from the US Gene Bank in 2008. From 2008 until 2015, these lines were selected for various features.In 2015 and 2016 at the Konya Bahri Dağdaş International Agricultural Research Institute, 5 standard varieties and 5 lines up yield experiment according to the "Randomized Complete Block Design" with four replication were established as four replications.

Significant differences were found between safflower lines every two years. In the same way, the analysis made by combining the years revealed the difference. According to the average of two years, BDYAS-9 line was placed in the first group with seed yield (302 kg/da). Followed by Dinçer and Göktürk varieties with $289 \mathrm{~kg} / \mathrm{da}$ and $285 \mathrm{~kg} / \mathrm{da}$ respectively.In terms of oil ratio, BDYAS-9 line was in the first place with $37.7 \%$ fat ratio. Followed by Olas with $37 \%$ and Linas with $35.1 \%$. According to the average of two years, the oil yield was obtained $113.5 \mathrm{~kg} / \mathrm{da}$ from BDYAS-9, $100 \mathrm{~kg} / \mathrm{da}$ from Olas variety, $95 \mathrm{~kg} / \mathrm{da}$ from Linas variety and $90 \mathrm{~kg} / \mathrm{da}$ from Balc1 variety. The development of varieties with superior characteristics than the existing varieties in terms of seed yield, fat content and oil yield, economically producing crops in ion is important both for farmers and for industrialists.

Key Words: Safflower, selection, variety, breeding

\section{GİRIS}

Aspir (Carthamus tinctorius L., Compositeae), 3000 y1l önce Ortadoğu'da kültüre alınmaya başlamış önemli bir yağ bitkisidir. Tohumlarında \% 90'1 doymamış yağ asitlerinden (oleik ve linoleik asit) oluşan \% 25-45 arasında yağ, \% 32-34 karbonhidrat, \% 14-15 protein, \% 5-8 nem ve \% 2-7 kül ihtiva etmektedir (Weiss, 2000; Çoşge vd., 2007).

Bitkisel yă̆ Aspir diğer yağ bitkilerine göre kış ayları serin ve yaz ayları kurak olan bölgelerde adaptasyon yeteneği oldukça yüksek bir bitkidir.
Özellikle tuzluluğa, kurağa ve nispeten de soğuğa olan yüksek toleransı nedeniyle Türkiye'nin kurak ve yarı kurak tarım alanlarında değerlendirilebilecek alternatif ürünlerden birisidir (Baydar ve Erbaş, 2007). Ülkemizin giderek artan yağ açığı dikkate alınacak olursa, aspir bitkisinin özellikle geniş alanlarda ticari olarak yetiştirilmesi durumunda hem üretici ve hem de sanayici isteklerine cevap verebilecek bir potansiyeli bulunmaktadır. Ancak mevcut aspir çeşitlerinin verimleri ve yağ oranları istenilen seviyede değildir. Aspirde her ne kadar 1slah çalışmaları ile yüksek yağ 
içeren (\% 40'ın üzerinde) çeşitler geliştirilmiş olsa da, üretimi yapılan aspir çeşitlerinin yağ içeriği bu seviyenin altında kalmaktadır (Johnson vd., 1999). Yeni geliştirilen aspir çeşitlerinde yă oranı nispeten artırılmış olsa da aspirin ayçiçeği, soya ve kanola gibi ürünlerle rekabet edebilmesi ve ekonomik olarak ürün elde edilmesi için tohum ve yağ verimi yă oranı yüksek aspir çeşitlerinin geliştirilmesi gerekmektedir.

Yağ açığının kapatılmasında, geniş adaptasyon kabiliyeti sayesinde tarımsal yönden en kolay yetiştirilme imkanına sahip olan yağ bitkisi aspirdir. Aspir ekiminin yaygınlaştırılması yağ bitkileri tarımı açısından önemli katkı sağlayacaktır (Ekiz ve Bayraktar 1986).

Aspirde en önemli ıslah amaçları arasında; yüksek tohum verimi, yüksek yăg verimi, erkencilik, düşük kabuk oranı ve yüksek yağ içeriği, yüksek linoleik veya yüksek oleik asit oranı, makineli hasada uygunluk ve hastalık ve zararlılara karşı dayanıklılık sayılabilir (Knowles, 1982; Röbbelen vd., 1989; Weiss, 2000). Diğer kültür bitkilerinde olduğu gibi, yukarıda sayılan 1slah amaçları doğrultusunda, geliştirilen aspir çeşit ve hatlarının en başta farklı çevre koşullarında stabil bir üretime izin verecek şekilde adaptasyon yeteneğinin ve verim performansının yüksek olması gerekir.

Türkiye'nin farklı bölgelerinde aspir genotiplerinin agronomik performansları ile ilgili pek çok çalışma yapılmıştır (Esendal 1973; Kolsarıcı 1983; Uslu ve ark. 1996; Gündoğdu 1997; Tunçtürk1998; Çalışkan ve ark. 1998;Kızıl ve ark. 1999; Kızıl 2002; Kaya ve ark. 2003; Çamaş ve ark. 2005; Uysal 2006; Karaaslan ve Hakan 2007; Polat 2007; Şaşt12007; Öztürk ve ark. 2008).

Türkiye'de bugüne kadar aspir yetiştiriciliğinde ve araştırmalarında yaygın olarak Dinçer 5-118, Remzibey05, Yenice 5-38 ve Balcı (son 2 yıl) çeşitleri kullanılmıştır. Her ne kadar bu çeşitler sınırlı üretim alanlarında ihtiyaca cevap vermiş olmakla birlikte, aspir tarımının yaygınlaşmasına bağlı olarak gittikçe farklılaşan agro-ekolojik koşullara daha iyi adapte olabilen ve daha yüksek tohum ve yağ verimi alınabilen yeni aspir çeşitlerine ihtiyaç duyulmaktadır.

Aspir ıslah çalışmalarında en önemli problemlerden birisi yerel materyalin özellikle yă̆ oranı açısından varyasyonunun dar olmasıdır. Bu çalışma da yurt dışı kökenli 245 adet hattan seleksiyonla elde edilen, ileri kademe hatların tescilli çeşitlerle verim ve verim unsurları açısından karşılaştırılması yapılmıştır.

\section{MATERYAL ve METOT}

$\mathrm{Bu}$ çalışma, Konya ekolojik şartlarında 2008-2016 yılları arasında yürütülen aspir ıslah çalışmalarının bir kısmını ihtiva etmektedir. ABD Gen Bankasından temin edilen farklı orijinli aspir popülasyonlarından seleksiyonla elde edilmiş 245 adet tek bitki ayrı sıralar halinde ekilmiştir.

2008 yıl1 ve 2015 yılları arasında yapılan seleksiyon çalışmalarıyla bu hatların sayısı 5'e kadar düşürülmüştür. 2015 ve 2016 yıllarında 5 adet standart çeşit (Göktürk, Balc1, Linas, Olas, Dinçer) ve 5 adet hatla (106-2, 11-1, 77-1-d, 89-1-c,BDYAS-9), tesadüf blokları deneme desenine göre dört tekerrürlü olarak Konya Bahri Dağdaş Uluslararası Tarımsal Araştırma Enstitüsü deneme tarlalarında verim denemesi kurulmuştur.

Araştırma "Tesadüf Blokları" deneme deseninde üç tekerrürlü olarak tertiplenmiş, ekimler; her iki yılda da nisan ayının ilk haftasında, $20 \mathrm{~cm}$ sıra arası mesafe ile 5 $\mathrm{m}$ parsel boyunda 6 sira olacak parsel mibzeri ile yapılmıştır. Hasat bitkiler olgunlaştığı zaman ağustos ayının üçüncü haftasında yapılmıştır. Araştırmada; çiçeklenme gün sayısı, olgunlaşma gün sayısı, bitki boyu, ham yağ oranı, tohum verimi ve ham yağ verimi, bin dane ağırlığı ele alınmıştır.

Araştırmada ele alınan özelliklerden sadece tohum verimi değerleri için, JUMP istatistik programında yıllar ayrı ayrı ve birleştirilerek varyans analizine tabi tutulmuş, "F" testi yapılmak suretiyle farlılıkları tespit edilen işlemlerin ortalama değerleri "LSD" önem testine göre gruplandırılmıştır. Tohum verimi dişındaki diğer gözlem ve ölçümlerde ortalama değerler alınmıştır.

\section{BULGULAR ve TARTIŞMA}

Çizelge1'de görüldüğü gibi Ortalama bitki boyu değerlerini incelediğimizde iki yıl ortalamasına göre 85 $\mathrm{cm}$ ile linas çeşidi ilk sırada yer alırken, bunu $83 \mathrm{~cm}$ ile BDYAS-9 ve 11-1 hatları takip etmiştir. En düşük bitki boyu ise $71 \mathrm{~cm}$ ile 106-2 hattından elde edilmiştir.

Makinalı hasada uygun olması açısından ideal aspir tiplerinin $60-85 \mathrm{~cm}$ boyunda olmasi arzu edilmektedir (Weiss 2000). Araştırmada değerlendirilen tüm hat ve çeşitler iki yılda da belirtilen sınırlar içerisinde yer almışlardır.

Çiçeklenme gün sayısı değerleri iki yıl ortalamasına göre en düşük 70 gün ve en yüksek 74 gün arasında değişmiştir. Çiçeklenme gün sayısı açısından hat ve çeşitlerde dar bir varyasyon olduğu tespit edilmiştir. Çiçeklenme gün sayısı erkencilik veya geçciliğin tespitinde önemli bir kriterdir. Yine aynı şekilde olgunlaşma gün sayısı da 112.5 ile 113.5 arasında değişmiştir.

Çizlelge.2'de görüldüğü gibi yăg oranı bakımından BDYAS-9 nolu hattımız \%37.7 lik yağ oranı ile birinci sırada yer almış, bunu \%37 ile Olas ve \% 35.1 ile Linas çeşitleri takip etmiştir. Çiftçi ve sanayici isteklerine bir arada cevap verebilmesi bakımından yüksek tohum verimi ve yăg oranın birlikte ele alındığı dekara yağ verimi de önem arz etmektedir. İki yıl ortalamasına göre BDYAS-9 nolu hattımızdan $113.5 \mathrm{~kg} /$ da yağ verimi elde edilirken, Olas çeşidinden 100, Linas çeşidinden 95, Balcı çeşidinden $90.5 \mathrm{~kg} / \mathrm{da}$ yağ verimi elde edilmiştir. Nagaraj ve Reddy (1997), aspir çeşitlerinin yă oranlarının değişimlerindeki en önemli faktörün yetiştirme şartlarından kaynaklanabileceğini, bunun yanında; olgunlaşma, kabuk miktarı ve çeşidin genotipik durumunun da aspir bitkisinin kalitesinin ve tohum yă içeriğinde önemli oranda etkili olacağını bildirmiştir. Bin tohum ağırlığı en yüksek standart çeşitlerden Göktürk ve Linas çeşitlerinden (43 g) elde edilmiştir. 
Çizelge.1. Hat ve çeşitlerin bitki boyu, çiçeklenme gün sayısı ve olgunlaşma gün sayısı değerleri.

\begin{tabular}{|l|c|c|c|c|c|c|c|c|c|}
\hline & \multicolumn{3}{|c}{ Bitki Boyu(cm) } & \multicolumn{3}{c|}{ Çiçeklenme Gün Sayısı } & \multicolumn{2}{c|}{ Olgunlaşma Gün Sayısı } \\
\cline { 2 - 11 } Çeşitler & $\mathbf{2 0 1 5}$ & $\mathbf{2 0 1 6}$ & Ortalama & $\mathbf{2 0 1 5}$ & $\mathbf{2 0 1 6}$ & Ortalama & $\mathbf{2 0 1 5}$ & $\mathbf{2 0 1 6}$ & Ortalama \\
\hline $106-2$ & 81 & 61 & $\mathbf{7 1}$ & 75 & 69 & $\mathbf{7 2}$ & 115 & 110 & $\mathbf{1 1 2 . 5}$ \\
\hline $11-1$ & 97 & 69 & $\mathbf{8 3}$ & 76 & 72 & $\mathbf{7 4}$ & 115 & 112 & $\mathbf{1 1 3 . 5}$ \\
\hline $77-1-d$ & 90 & 70 & $\mathbf{8 0}$ & 74 & 69 & $\mathbf{7 1}$ & 115 & 110 & $\mathbf{1 1 2 . 5}$ \\
\hline $89-1-c$ & 84 & 62 & $\mathbf{7 3}$ & 74 & 69 & $\mathbf{7 1}$ & 115 & 110 & $\mathbf{1 1 2 . 5}$ \\
\hline Balc1 & 81 & 69 & $\mathbf{7 5}$ & 74 & 70 & $\mathbf{7 2}$ & 115 & 110 & $\mathbf{1 1 2 . 5}$ \\
\hline BDYAS-9 & 98 & 68 & $\mathbf{8 3}$ & 74 & 72 & $\mathbf{7 3}$ & 115 & 110 & $\mathbf{1 1 2 . 5}$ \\
\hline Dinçer & 90 & 70 & $\mathbf{8 0}$ & 76 & 71 & $\mathbf{7 3}$ & 115 & 112 & $\mathbf{1 1 3 . 5}$ \\
\hline GÖKTÜRK & 85 & 65 & $\mathbf{7 5}$ & 73 & 68 & $\mathbf{7 0}$ & 115 & 109 & $\mathbf{1 1 2 . 0}$ \\
\hline LiNAS & 93 & 77 & $\mathbf{8 5}$ & 76 & 72 & $\mathbf{7 4}$ & 115 & 112 & $\mathbf{1 1 3 . 5}$ \\
\hline OLAS & 73 & 73 & $\mathbf{7 3}$ & 75 & 71 & $\mathbf{7 3}$ & 115 & 112 & $\mathbf{1 1 3 . 5}$ \\
\hline
\end{tabular}

Çizelge.2. Hat ve çeşitlerin yağ oranı, yağ verimi ve bin tohum ağırlığı değerleri

\begin{tabular}{|c|c|c|c|c|c|c|c|c|c|}
\hline & \multicolumn{3}{|c|}{ Yă̆ Oranı (\%) } & \multicolumn{3}{|c|}{ Yağ Verimi(kg/da) } & \multicolumn{3}{|c|}{ Bin Tohum Ăğırlığı (g) } \\
\hline Çeşitler & 2015 & 2016 & Ortalama & 2015 & 2016 & Ortalama & 2015 & 2016 & Ortalama \\
\hline $106-2$ & 36.6 & 33.2 & 34.9 & 98 & 67 & 82.5 & 39 & 40 & 39.5 \\
\hline $11-1$ & 32.3 & 31.2 & 31.7 & 92 & 63 & 77.5 & 40 & 41 & 40.5 \\
\hline $77-1-d$ & 34.0 & 33.9 & 33.9 & 89 & 62 & 75.5 & 37 & 36 & 36.5 \\
\hline $89-1-c$ & 36.3 & 34.0 & 35.1 & 102 & 54 & 78.0 & 41 & 42 & 41.5 \\
\hline Balc1 & 34.6 & 34.5 & 34.5 & 99 & 82 & 90.5 & 41 & 43 & 42.0 \\
\hline BDYAS-9 & 37.4 & 38.0 & 37.7 & 133 & 94 & 113.5 & 42 & 42 & 42.0 \\
\hline Dinçer & 29.7 & 27.3 & 28.5 & 100 & 64 & 82.0 & 43 & 43 & 43.0 \\
\hline GÖKTÜRK & 33.0 & 33.9 & 33.5 & 116 & 74 & 95.0 & 43 & 43 & 43.0 \\
\hline LINAS & 35.0 & 35.2 & 35.1 & 97 & 93 & 95.0 & 40 & 42 & 41.0 \\
\hline OLAS & 36.7 & 37.2 & 37.0 & 115 & 85 & 100.0 & 41 & 41 & 41.0 \\
\hline
\end{tabular}

Çizelge.3. Hat ve çeşitlerin tohum verimi değerleri.

\begin{tabular}{|c|c|c|c|}
\hline Çeşitler & 2015 & 2016 & Ortalama \\
\hline BDYAS-9 & $357 \mathbf{a}$ & $248 \mathrm{ab}$ & 302 a \\
\hline Dinçer & $344 \mathrm{ab}$ & $234 \mathrm{bc}$ & 289 ab \\
\hline Göktürk & $353 \mathrm{ab}$ & $217 \mathrm{~cd}$ & 285 ab \\
\hline Linas & $278 \mathrm{~cd}$ & $265 \mathrm{a}$ & 271 bc \\
\hline Olas & $313 \mathrm{bc}$ & 229 bc & 271 bc \\
\hline Balcı & $287 \mathrm{~cd}$ & $238 \mathrm{bc}$ & $262 \mathrm{~cd}$ \\
\hline 11-1 & $285 \mathrm{~cd}$ & $203 \mathrm{de}$ & 244 de \\
\hline $106-2$ & $269 \mathrm{~d}$ & $202 \mathrm{de}$ & 235 ef \\
\hline 77-1-d & $262 \mathrm{~d}$ & 182 ef & 222 ef \\
\hline 89-1-c & $281 \mathrm{~cd}$ & $157 \mathrm{f}$ & $219 \mathrm{f}$ \\
\hline $\mathrm{VK}(\%)$ & 9 & 8 & 8.5 \\
\hline LSD & 38 & 25 & 22 \\
\hline
\end{tabular}


Çizelge.4. Tohum Verimi Değerlerinin Yılların Ayrı Ayrı Varyans Analiz Sonuçları

\begin{tabular}{|l|l|l|l|l|}
\hline & & $\mathbf{2 0 1 5}$ & $\mathbf{2 0 1 6}$ \\
\hline $\begin{array}{l}\text { Varyasyon } \\
\text { Kaynağ }\end{array}$ & SD & KO Pr>F & KO Pr>F & \\
\hline Tekrarlar & 3 & 7000,4390 & $1748^{* *} \quad 0.0040$ \\
\hline Çeşitler & 9 & $5192^{* *}<, 0.0001$ & $4133^{* *} \quad<, 0.0001$ \\
\hline Hata & 27 & 751 & 311 & \\
\hline Genel & 39 & 1772 & 1303 & \\
\hline CV $(\%)$ & & \multicolumn{1}{|c|}{9} & 8 & \\
\hline
\end{tabular}

Çizelge.5. Tohum Verimi Değerlerinin Yılların Birleştirilmiş Varyans Analiz Sonuçları

\begin{tabular}{|c|c|c|c|}
\hline $\begin{array}{c}\text { Varyasyon } \\
\text { Kaynağı }\end{array}$ & SD & KO & Pr>F \\
\hline Yıllar & 1 & 145504 & $<.0001$ \\
\hline Tekrarlar & 3 & 2260 & 0,0074 \\
\hline Çeşitler & 9 & 6627 & $<.0001$ \\
\hline ÇeşitlerxY11 & 9 & 2698 & $<.0001$ \\
\hline Hata & 57 & 513 & \\
\hline Genel & 79 & 3360 & \\
\hline
\end{tabular}

Çizelge.3, Cizelge4 ve Cizelge.5 incelendiğinde tohum verimi bakımından aspir hatları arasında her iki yılda da önemli farklılıklar bulunmuştur. Aynı şekilde yılların birleştirilmesi ile yapılan analiz de farklılığı ortaya koymuştur. İki yıl ortalamasına göre BDYAS-9 nolu hattımız $302 \mathrm{~kg} / \mathrm{da}$ tohum verimi ile ilk grupta 1. Sirada yer alırken, bunu sirasiyla $289 \mathrm{~kg} / \mathrm{da}$ ve 285 $\mathrm{kg} / \mathrm{da}$ ile Dinçer ve Göktürk çeşitleri takip etmiş̧tir.

\section{SONUC}

Araştırma sonucunda tohum verimi açısından aspir hatları arasında her iki yılda da önemli farklılıklar bulunmuştur. Aynı şekilde yılların birleştirilmesi ile yapılan analiz de farklılığı ortaya koymuștur. BDYAS-9 nolu hattımız tohum verimi bakımından ilk yıl ilk sırada yer alırken, ikinci yıl ikinci grupta yer almıştır. Yıllar ortalaması olarak ta ilk sırada yer almıştır. Yağ oranı ve yağ verimi bakımından da yıllar ayrı ayrı ve iki yıl ortalamasında da ilk sırada yer almıştır. Yağlı tohumlu bitkilerden aspirin en önemli sorunlarından biriside düşük verim ve düşük yağ içeriğidir. Çiftçi ve sanayici isteklerine bir arada cevap verebilmesi bakımından yüksek tohum verimi ve yağ oranın birlikte ele alındığı dekara yağ verimi de önem arz etmektedir.

Tohum verimi, yağ oranı ve yağ verimi açısından tercih edilecek olan BDYAS-9 nolu hattımız tescil açısından ümitvar görünmektedir.

\section{KAYNAKLAR}

Baydar H, Erbaș S 2007. "Türkiye'de yemeklik yağ ve biyodizel üretimine uygun aspir 1slahı", 1.Ulusal Yağlı Tohumlu Bitkiler ve Biyodizel Sempozyumu, 28-31 Mayıs 2007, Samsun, Sunulu Bildiriler, 378386.
Çoşge B, Gürbüz B, Kıralan M 2007. "Oil content and fatty acid composition of some safflower (Carthamus tinctorius L.) varieties sown in spring and winter", International Journal of Natural and Engineering Sciences, 1(3),11-15.

Çamaş N, Ayan A.K, Çırak C 2005. Relationships between seed yield and some characters of safflower (Carthamus tinctorius L.) cultivar in the Middle Black Sea conditions. Proceedings VIth International Safflower Conference, 6-10 June, İstanbul-Turkey.

Çalışkan M.E, Mert A, Mert M, İşler N 1998.Evaluation of some safflower (Carthamus tinctorius L.) cultivars for morpho-agronomic characters under Hatay ecological conditions. Tr. J. of Field Crops, 3:2, 51-54.

Ekiz E, Bayraktar N (1986). Kendileme Aspir (Carthamus tinctorius L.) Hatların Eşleme (Coupled) Yöntemiyle Açıkta Tozlanmasından Elde Edilen Seçimi ve Kuru Tarım Bölgelerine Adaptasyonu. TÜBITTAK TAOG KBTBAÜ-19 Ankara.

Esendal E 1973. Erzurum ekolojik şartlarında yetiştirilen bazı yerli ve yabancı aspir (Carthamus tinctorius L.) çeşitlerinin fenolojik ve morfolojik karakterleri ile verimleri ve tohum özellikleri üzerinde bir araştırma. Atatürk Üniv. Yay. No: 310 Ziraat Fak. Yay. No: 151 Araştırma Serisi No: 88, Sevinç Matbaas1, Ankara.

Gündoğdu F 1997. Bazı Aspir (Carthamus tinctorius L.) çeşitlerinde farklı azot dozlarının verim ve kalite üzerine etkileri. Uludağ Üniv. Fen Bilimleri Ens., Tarla Bit.Anabilim Dalı, Y. Lisans Tezi, 85 s., Bursa. 
Johnson R.C, Bergman J.W, Flynn C.R 1999. Oil and meal characteristics ofcore and non-core safflower accessions from the USDA collection. Genet. Res. Crop Evol., 46:611-618.

Karaaslan D, Hakan M 2007. Diyarbakır koşullarında aspir için en uygun yazlık ekim zamanının ve çeşitlerinin belirlenmesi. Türkiye VII. Tarla Bitkileri Kongresi, 25-27 Haziran, 665-669, Erzurum.

Kaya M.D, İpek A, Özdemir A 2003. Effects of different soil salinity levels on germination and seedling growth of safflower (Carthamus tinctorius L.). Tr. J. Agri. and

Forestry, 27:221-227.

Kızıl S, Toncer Ö, Söğüt T 1999. Diyarbakır koşullarında farklı sıra aralığı mesafelerinin aspir (Carthamus tinctoriusL.)'de verim ve verim unsurlarına etkisi. Türkiye III. Tarla Bitkileri Kongresi Bildirileri, 15-18 Kasım, Cilt 2, Endüstri Bitkileri, 358-362, Adana.

Kızıl S 2002. Diyarbakır ekolojik koşullarında aspir (Carthamus tinctorius L.)'de uygun ekim zamanının belirlenmesi üzerine bir çalışma. Ege Tarımsal Araştırma Enst. Dergisi, 12 (1):37-50.

Knowles P.F 1982. Safflower: Genetics and breeding. 1n: improvement of oilseed and industrial crops by induced mutations. International Atomic Energy Agency, 89-101, Vienna.

Kolsarıcı Ö, Ekiz E 1983. Yerli ve yabancı kökenli aspir (Carthamus tinctorius L.) çesitlerinin önemli tarımsal özellikleri üzerinde araştırmalar. Ankara Üniv. Zir. Fak. Yayınları:864, 25 s., Ankara.

Nagaraj G, ve Reddy PS (1997) Soma Factors Influencing Safflower Seed and Oil Quality. IV. International Safflower Conference. (2-7 June 1997), 347-349. Italy
Öztürk E, Özer H, Polat T 2008. Growth and yield of safflower genotypes grown under irrigated and nonirrigated conditions in a highland environment. Plant Soil Environ.54, 2008 (10): 453-460.

Polat T 2007. Farklı sira aralıkları ve azot seviyelerinin kuru şartlarda yetiştirilen aspir (Carthamus tinctorius L.) bitkisinin verim ve verim unsurları üzerine etkisi. Doktora Tezi. Atatürk Üniv. Fen Bil. Enst., Erzurum.

Robbelen G, Downey R.K, Ashri A 1989. "Oilcrops of the world", McGraw Hill Books, USA.

Şaştı H 2007. Kahramanmaraş koşullarında farklı miktarlarda ve zamanlarda uygulanan azotun aspir (Carthamus tinctoriusL.)'de tohum vrimi, verim unsurlar, yağ oranı ve tohumun makro-mikro element içeriğine etkisi. Y. Lisans Tezi, KSU,Fen Bil. Enst., Kahramanmaraş.

Tunçtürk M 1998. Van ekolojik koşullarında azotlu gübre form ve dozlarının aspir (Carthamus tinctorius L.)'de verim ve verim unsurları üzerine etkisi. Y. Lisans Tezi, Y.Y.Ü. Fen Bil. Enst., Van.

Uslu, N, Akın A, Halitligil M.B 1996. Cultivar, weed and row specing effects on some agronomic characters of safflower (Carthamus tinctorius L.) in spring planting. Tr. J. of Agriculture of Forestry. 22:533-536

Uysal N, Baydar H, Erbaş S 2006. Isparta populasyonundan geliștirilen aspir (Carthamus tinctorius L.) hatlarının tarımsal ve teknolojik özelliklerinin belirlenmesi. Süleyman Demirel Üniv. Zir. Fak. Dergisi 1(1):52-63.

Weiss E.A 2000. Safflower. In: Oilseed Crops, Blackwell Sci. Ltd., Victoria, Australia, pp 93-129. 